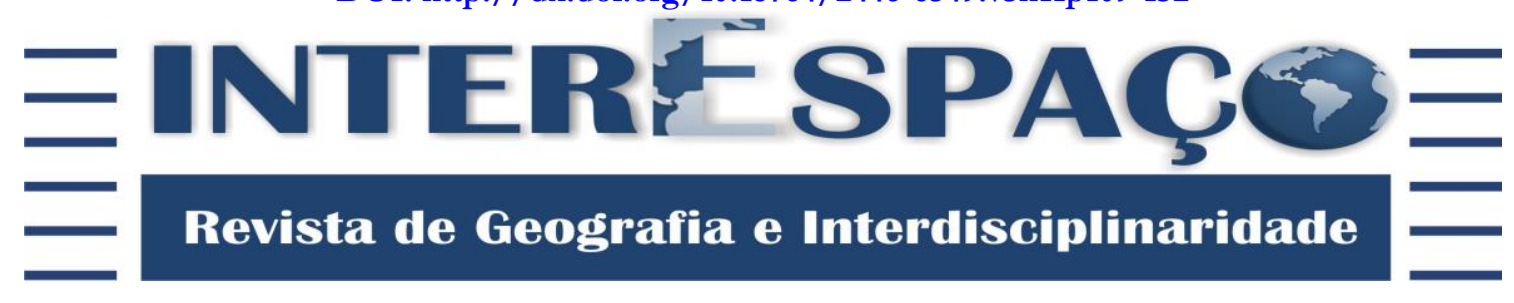

\title{
A ATIVIDADE LÚDICA NO DESENVOLVIMENTO DA CRIANÇA: contribuições de Elkonin para a Educação Física Escolar
}

\section{LUDIC ACTIVITY IN CHILD DEVELOPMENT: Elkonin's contributions to scholar physical education}

\section{LA ACTIVIDAD LÚDICA EN EL DESARROLLO DEL NIÑO: contribuciones de Elkonin para la educación física escolar}

\section{Cíntia Regina de Fátima}

Doutoranda e Mestra em Educação (Psicologia da Educação) pela Pontifícia Universidade Católica de São Paulo - PUC/SP. Licenciada em Educação Física - UFVJM.

cintiadtna@hotmail.com

Flávia Gonçalves da Silva

Psicóloga. Doutora em Educação (Psicologia da Educação) pela Pontifícia Universidade Católica de São Paulo - PUC/SP. Professora da Universidade Federal dos Vales do Jequitinhonha e Mucuri -

UFVJM.

flaviagonsalves@yahoo.com.br

Recebido para avaliação em 24/02/2017; Aceito para publicação em 28/11/2017.

\section{RESUMO}

As atividades lúdicas, como conteúdo curricular da Educação Física, ao mesmo tempo em que propiciam momentos de lazer e recreação, também representam formas pedagógicas de promover o ensino, uma vez que fazem parte do conteúdo da cultura corporal. A partir disso, o objetivo deste trabalho foi estudar as concepções de atividades lúdicas na perspectiva de Elkonin, compreender sua relação com os processos de desenvolvimento e aprendizagem e relaciona-las aos conteúdos da Educação Física escolar na educação infantil. Este estudo foi feito a partir da análise da principal obra de Elkonin - Psicologia do jogo - e dos objetivos da educação física na educação infantil colocados nos documentos oficiais do MEC e da concepção sobre a cultura corporal. A atividade lúdica, para Elkonin, é a representação de um papel e o uso de um objeto subentendendo outro. É por meio do jogo que a criança apreende a realidade e desenvolve as funções psíquicas, possibilitando sua ação consciente no mundo. Sob este ponto de vista apresenta-se a importância das atividades lúdicas no desenvolvimento da criança e algumas estratégias pedagógicas que visam facilitar o ensino da educação física. Conclui-se que há a necessidade do professor de educação física compreender o indivíduo em sua totalidade e, em função disso, ensinar a cultura corporal para além do aspecto motor, contribuindo, intencionalmente, para o desenvolvimento da criança. Torna-se assim oportuna a concepção do educar pelo movimento, superando as teorias que se limitam à compreensão de corpo versus mente, ainda recorrente na prática pedagógica do professor de educação física.

Palavras-chave: Educação Física; Psicologia Histórico-Cultural; Ensino-Aprendizagem; Desenvolvimento.

\section{ABSTRACT}

The ludic activities, as Physical Education curricular content, propitiate at the same time leisure and recreation moments and also represent pedagogical ways to promote learning, once it is part of the body culture content. Thereof, the purpose of this paper was to study the Ludic Activities 


\section{Dossiê: Diálogos interdisciplinares em Psicologia da Educação \\ | A atividade lúdica no desenvolvimento da criança: contribuições de Elkonin para a Educação}

Física Escolar|

\section{| Cíntia Regina de Fátima | Flávia Gonçalves da Silva |}

conceptions in Elkonin's perspectives, to comprehend its relation to learning and development processes and to relate these conceptions to scholar Physical Education contents in early childhood education. This study was done from the analysis of Elkonin's main work - Psychology of play from the physical education purposes in childhood education used in Brazilians' educational official documents and from the body culture conception. To Elkonin, the ludic activity is the representation of a role and the use of one object being understood as other. It is through the game/play that child apprehends the reality and assimilates psyche functions, enabling its conscious action in world. In this way, it is learning that boosts development and not the opposite. Under this point of view it is shown the ludic activity importance in child development and some pedagogical strategies that look for facilitate the body culture contents teaching. We conclude that the physical education teacher must comprehend the individual in its totality and, because of this, teach physical education over and above motor aspects, contributing, intentionally, to child development. In this way it makes opportune the conception to educate through movement, overcoming the theories that are limited to the comprehension of body versus mind, still recurrent in the physical education teacher's pedagogical practice.

Keywords: Physical Education; Historical-cultural Psychology; Teaching-Learning; Development.

\section{RESUMEN}

Las actividades lúdicas, como contenido curricular de la Educación Física, mientras ofrecen momentos de recreación también representan formas pedagógicas de fomentar la enseñanza, ya que hacen parte del contenido de la cultura corporal. A partir de eso, el objetivo de este trabajo fue estudiar las concepciones de actividades lúdicas en la perspectiva de Elkonin, comprender su relación con los procesos de desarrollo y aprendizaje y relacionarlas a los contenidos de la Educación Física escolar en la educación infantil. Este estudio se hizo a partir del análisis de la principal obra de Elkonin - Psicología del juego - y de los objetivos de la educación física en la educación infantil colocados en los documentos oficiales del MEC y de la concepción sobre la cultura corporal. La actividad lúdica, para Elkonin, es la representación de un papel y el uso de un objeto deduciendo otro. Es a través del juego que el niño aprehende la realidad y desarrolla las funciones psíquicas, permitiendo su acción consciente en el mundo. Desde este punto de vista se presenta la importancia de las actividades lúdicas en el desarrollo infantil y algunas estrategias pedagógicas que tienen por objetivo facilitar la enseñanza de la educación física. Se concluye que hay la necesidad del profesor de educación física comprender al individuo en su totalidad y, por eso, enseñar la cultura corporal más allá del aspecto motor, contribuyendo, intencionalmente, al desarrollo del niño. Se vuelve así oportuna la concepción del educar por el movimiento, superando las teorías que se limitan a la comprensión de cuerpo versus mente, aún recurrente en la práctica pedagógica del profesor de educación física.

Palabras clave: Educación Física; Psicología Histórico-Cultural; Enseñanza-Aprendizaje; Desarrollo.

\section{INTRODUÇÃO}

As atividades lúdicas, no campo da Educação Física, ao mesmo tempo em que podem propiciar momentos de lazer e recreação, também representam formas pedagógicas de promover o ensino, uma vez que fazem parte dos conteúdos da cultura corporal. Diversos autores, vinculados à Educação Física, versam sobre a importância dos jogos e brincadeiras na infância. Para Pinto (1996), o jogo lúdico é polissêmico, portanto possui diferentes concepções, dependendo do contexto em que está inserido. O autor ainda cita que, ao brincar, o corpo sintetiza o lúdico e faz a seguinte reflexão: 


\section{| Cíntia Regina de Fátima | Flávia Gonçalves da Silva |}

[...] o lúdico, no meu entender, materializa a experiência sociocultural movida pelos desejos de quem joga e coroada pelo prazer. Prazer que se funde no exercício da liberdade e, por isso, representa conquista de quem pode sonhar, sentir, decidir, arquitetar, aventurar e agir, esforçando por superar desafios da brincadeira, consumindo o processo do brinquedo, recriando o tempo, o lugar e os objetos em jogo e usufruindo do seu produto, que, em sua exuberância é uma festa (PINTO, 1996, p. 96).

O principal atributo do brincar está no alvo: se concentrar no processo e não no resultado da ação. Kishimoto (1996) faz a distinção entre jogo esportivo e jogo infantil. O primeiro direciona seus objetivos à formação e à competição, sendo o vencer a finalidade para a prática; já o segundo refere-se às brincadeiras, que têm como alvo o processo em si e não o resultado.

Nista-Piccolo e Moreira (2012) mencionam a importância do jogo na educação infantil e o destaca como atividade educativa que permite vivenciar o risco e também a fantasia, assim como o aprender pelo prazer. Para os referidos autores, o jogo não possui necessariamente a capacidade de ensinar conhecimentos específicos, como os conteúdos das demais disciplinas oferecidas na escola, entretanto, é o que possui maior capacidade de educar, no sentido de tornar os indivíduos mais humanos.

Embora a ludicidade não seja atividade exclusiva da educação física, ela se caracteriza como uma das suas especificidades. A educação física, que tem como eixo norteador a cultura corporal, possui um modelo de dinâmica curricular distinto das demais disciplinas, tendo em vista que seu objeto de reflexão pedagógica é a linguagem corporal, isto é, representações simbólicas da realidade, construídas historicamente e cristalizadas em forma de movimento corporal significado ou, nas palavras do Castellani Filho et al. (2001), de expressão corporal (que são os jogos e brincadeiras, danças, lutas, capoeira, ginástica, entre outros).

De acordo com a Lei de Diretrizes e Bases da Educação Nacional - LDB (BRASIL, 1996), a educação física é regulamentada como disciplina obrigatória da Educação Infantil, contudo não menciona a obrigatoriedade na contratação do professor especialista. Para Ayoub (2005), a inserção da Educação Física no currículo da Educação Infantil, que tem atende crianças entre 0 a 6 anos de idade, se caracteriza como um tema bastante polêmico, tanto no que diz respeito à presença da disciplina Educação Física nas creches e pré-escolas, como os diferentes professores, generalistas e especialistas, que atuam nesse contexto. Segundo a autora, deve-se pensar, para a função de ministrar aulas, não em professores generalistas, que desenvolvem diversas atividades curriculares, ou especialistas, que ministram aulas específicas, mas em professores de Educação Infantil que, ao compartilharem saberes, atuam juntos na formação das crianças. Assim, apesar das 
| Cíntia Regina de Fátima | Flávia Gonçalves da Silva |

dificuldades que se encontram, é importante a presença de diferentes áreas de formação na Educação Infantil, porém de forma a trabalharem mútua e coletivamente (AYOUB, 2001).

O Referencial Curricular Nacional para a Educação Infantil - RCNEI - (BRASIL, 1998), publicado em 1998 e ainda utilizado como modelo, propõe metas de qualidade que contribuem para o desenvolvimento integral das crianças, visando à socialização e ampliação dos seus conhecimentos sobre a realidade social e cultural. Sendo assim, o RCNEI aponta que a prática da Educação Infantil deve ser organizada de tal forma que as crianças desenvolvam capacidades tais como: descobrir e conhecer o próprio corpo; se apropriar e utilizar diferentes linguagens, como a corporal, musical, oral, escrita, plástica, suas possibilidades de comunicação, processos históricos, valores e significados; brincar possibilitando a expressão de sentimentos, desejos e pensamentos. Importante mencionar que em 2013, a lei n 12.796 , de 4 de abril, altera a LDB n. 9394/96, tornando obrigatória a matrícula de toda criança na Educação Infantil a partir dos 4 anos, no nível pré-escolar, assim como as crianças de 5 anos (aos 6 anos já ingressa no primeiro ano do Ensino Fundamental). Além dessa alteração, a Educação Infantil passou a ter carga mínima de 800 horas, distribuídas ao longo de 200 dias letivos no ano, bem como a necessidade da criança frequentar pelo menos $60 \%$ da carga horária total. A equipe pedagógica deve elaborar documentos de avaliação que explicitem o desenvolvimento da criança (sem implicar em promoção ou retenção) (BRASIL, 2013).

Ao considerar a expressão corporal como uma forma de linguagem, Ayoub (2001) enfatiza que a Educação Física, inserida na Educação Infantil, por tratar pedagogicamente das danças, lutas, jogos, brincadeiras, artes e esportes, na Educação Infantil pode tornar esses conteúdos acessíveis à criança a partir do brincar, de forma a se alfabetizar nesta.

Sendo assim, este artigo tem como objetivo estudar as concepções de atividades lúdicas na perspectiva da psicologia histórico-cultural, precisamente na produção de Elkonin, compreender sua relação com os processos de desenvolvimento e aprendizagem e relacionar tais concepções aos conteúdos da Educação Física escolar, de modo a explicitar como estas podem promover o desenvolvimento quando trabalhadas na Educação Infantil. Esse texto não tem o propósito de criticar ou apresentar lacunas na produção do autor, mas refletir como suas proposições podem auxiliar o professor de Educação Física na prática pedagógica, superando a dicotomização corpo versus mente ainda presente na Educação Física.

A principal referência da concepção de Elkonin foi sua obra mais importante Psicologia do jogo - e dois textos encontrados apenas na língua espanhola - "Hacia el 


\section{| Cíntia Regina de Fátima | Flávia Gonçalves da Silva |}

problema de la periodización del desarrollo en la edad infantil" e "Problemas actuales en la psicología del juego en la edad pré-escolar”. Dentro dessa perspectiva, a leitura das obras de Elkonin foi realizada no sentido de identificar a concepção de desenvolvimento e aprendizagem, a concepção de atividades lúdicas e seu processo de desenvolvimento, a relação entre atividades lúdicas e os processos de desenvolvimento e aprendizagem para estabelecer possíveis contribuições para o ensino das atividades lúdicas como conteúdo curricular da Educação Física escolar e/ou para utilizá-las como meio pedagógico para o ensino de outros conteúdos. Essa relação foi possível ao considerar os objetivos da Educação Física, compreendida como cultura corporal, na Educação Infantil. A partir disso foi possível tecer contribuições da Educação Física no processo de constituição do indivíduo, especificamente da criança e, ao mesmo tempo, orientar, por meio dos conhecimentos da psicologia, o professor para melhorar qualitativamente sua aula.

\section{O PROCESSO DE CONSTITUIÇÃO DA CRIANÇA: a concepção de desenvolvimento e aprendizagem para Elkonin}

Daniil Borisovich Elkonin nasceu no ano de 1904, em Peretshepino, na Ucrânia, e faleceu em 1984. Em 1927, concluiu a graduação no curso de Psicologia pelo Instituto Pedagógico de Herzen. Fundamentado nos pressupostos de Vigotski, tornou-se um dos representantes da psicologia histórico-cultural. A principal obra do autor publicada em língua portuguesa e espanhola é a 'Psicologia do jogo', mas também são encontrados publicações de diversos estudos vinculados à periodização do desenvolvimento humano e ao processo educacional (LAZARETTTI, 2011).

O homem, enquanto um ser de natureza social, perpassa por estágios culturalmente determinados que, se organizados, permitem identificar as forças determinantes no desenvolvimento psicológico. Elkonin (2009a), a partir dos estudos de Leontiev, acredita que tais forças estão relacionadas com a atividade do indivíduo no mundo, seja ele adulto ou criança.

Dentre as diversas atividades que o indivíduo realiza, Elkonin (2009a) destaca a importância da atividade principal ${ }^{1}$, considerada fundamental em cada período, pois provoca transformações na pessoa e reestrutura seu modo de pensar e agir no mundo. Ela é a principal responsável pelas transformações qualitativas no desenvolvimento psicológico do indivíduo, muito embora não exclui as outras formas de atividades existentes.

\footnotetext{
${ }^{1} \mathrm{Na}$ obra Psicologia do Jogo o termo 'atividade principal' foi traduzido como atividade rectora.
} 


\section{| Cíntia Regina de Fátima | Flávia Gonçalves da Silva |}

A atividade principal do bebê é a comunicação emocional imediata estabelecida com os adultos. Na primeira infância (aproximadamente entre 1 e 2 anos), a atividade principal é basicamente ações com objetos, de tal forma que a comunicação emocional é secundarizada e a relação com o adulto está orientada pelo mundo objetal. Já na idade préescolar (em torno de 3 a 6 anos) tal atividade é incorporada pelos jogos de papéis, nos quais a criança representa as ações dos adultos e suas relações interpessoais (ELKONIN, 2009a). $\mathrm{Na}$ idade escolar (entre 7 e 12 anos), a atividade principal se refere à aprendizagem escolar, em que o objetivo principal está na aquisição de conhecimentos de forma sistematizada e, ao mesmo tempo, constitui as relações da criança com os adultos. $\mathrm{Na}$ adolescência, a referida atividade está vinculada à comunicação, voltada para a formação das relações íntimo-pessoal, que tem como base as determinações sociais que influenciam as atitudes do adolescente. A partir dessas relações, surgem os motivos e objetivos da próxima etapa que vão orientar as escolhas profissionais, projetadas para o futuro.

De modo geral, a atividade humana, segundo Elkonin (2009a), pode ser classificada a partir de dois sistemas de relações, sendo um predominante em relação ao outro (mas não excludente), a depender da fase do desenvolvimento em que o homem se encontra. $\mathrm{O}$ primeiro sistema estabelecido pelo autor é o da criança-adulto, base para aquisição de motivações e necessidades. O segundo é dado pela relação criança-objeto social, que será a base para a formação da dimensão intelectual cognitiva.

Todas as atividades mencionadas podem ser divididas entre os dois grupos apresentados pelo autor. O primeiro se refere ao sistema de relações criança-adulto social, no qual estão contidas a comunicação emocional do bebê, o jogo de papéis da idade préescolar e a comunicação íntimo-pessoal dos adolescentes. Em todos esses períodos, as atividades desenvolvem a esfera das motivações e necessidades, entretanto cada um deles possuem motivos e objetivos particulares. O segundo grupo, assinalado pelas relações criança-objeto social, é formado pelas atividades de manipulação objetal na primeira infância, aprendizagem escolar no período escolar e estudos profissionais no adolescente. As atividades que constituem esse grupo são semelhantes no que diz respeito à apropriação dos meios elaborados socialmente, no sentido de orientar as ações dos indivíduos sobre tais produções para a formação da esfera intelectual cognitiva.

Embora o desenvolvimento do indivíduo nos estágios do primeiro grupo esteja mais orientado pelas relações interpessoais e no segundo pelas suas ações no mundo, não significa que os períodos sejam determinados unilateralmente, mas que em dada época 
Dossiê: Diálogos interdisciplinares em Psicologia da Educação

| A atividade lúdica no desenvolvimento da criança: contribuições de Elkonin para a Educação

Física Escolar|

| Cíntia Regina de Fátima | Flávia Gonçalves da Silva |

existem modos de relações que vão predominar e contribuir de forma mais decisiva na constituição do psiquismo e na atuação do indivíduo no mundo.

Partindo das atividades principais, Elkonin (2009a) estrutura o desenvolvimento em três épocas e seis períodos. Para cada época correspondem dois períodos, sendo eles, respectivamente, primeira idade (recém-nascido e primeira infância), infância (idade préescolar e escolar menor) e adolescência (maior e menor). Elkonin (2009a) aponta também dois momentos críticos que podem ocorrer na transição de uma época a outra. Entre a primeira etapa e a infância pode ocorrer a crise dos três anos; do mesmo modo, entre a infância e a adolescência incide a crise da maturação sexual. As duas crises apresentam características análogas, pois em ambas surge o desejo de independência e manifestam-se atitudes negativas na relação com o adulto.

A estrutura qualitativa dentre as épocas, no que diz respeito ao sistema de relações predominante, é similar, de forma que o primeiro período sempre corresponde à esfera das relações criança-adulto e o segundo período é igualmente submetido ao sistema de relações criança-objeto social. Por exemplo, na infância (corresponde a uma época), as atividades do pré-escolar (corresponde a um período) estão inseridas na relação criança-adulto (corresponde a um sistema de relações), já no escolar se voltam para o sistema criançaobjeto social e assim sucessivamente, em todas as épocas.

Em função disso, durante todo o desenvolvimento infantil, as aquisições ora estão voltadas para as relações interpessoais, ora para a produção social, de tal forma que ambas se alternam entre os períodos (ELKONIN, 2009a). Por outras palavras, Elkonin (2009a) aponta que

[...] por un lado, periodos en los que se adquieren predominantemente los objetivos, los motivos y las normas de las relaciones entre las personas, y sobre esta base se desarrolla la esfera de motivaciones y necesidades. Por otro lado, hay períodos en los cuales se adquieren predominantemente los medios socialmente elaborados de las acciones con los objetos, y sobre esta base se forman las fuerzas intelectuales y cognitivas de los niños y sus posibilidades técnico-operacionales (ELKONIN, 2009a, p. 208).

Os significados práticos desta periodização estão relacionados à capacidade de identificar e solucionar os problemas das relações características de cada período e, ao mesmo tempo, se atentar para os problemas de interdependência entre os setores da educação, sobretudo no que se refere ao modelo educacional da idade pré-escolar e escolar que não possuem a articulação necessária. 
| Cíntia Regina de Fátima | Flávia Gonçalves da Silva |

Para Elkonin, a criança se desenvolve na relação com o mundo e as diferentes atividades vão determinar a sua consciência. Embora seus estudos tenham permitido estabelecer etapas do desenvolvimento, crises e períodos sensíveis para a aprendizagem de determinados conteúdos, afirma-se que é a ação da criança no mundo e sua relação com o outro que determina suas necessidades e a forma como são criadas e satisfeitas, transformando qualitativamente seu psiquismo. Nesse sentido, a periodização do desenvolvimento não está dada e não é determinada biologicamente, pois, o homem é um ser social.

\section{A CONCEPÇÃO DE ATIVIDAdE LÚdiCA E SUA RELAÇÃO COM A APRENDIZAGEM E O DESENVOLVIMENTO DA CRIANÇA}

$\mathrm{Na}$ busca por compreender a formação e o desenvolvimento da atividade principal na infância, especialmente na idade pré-escolar, este trabalho será direcionado para o estudo do jogo protagonizado, correspondente ao período mencionado. A propósito, a atividade será abordada desde a sua origem até as possíveis contribuições que pode oferecer ao desenvolvimento infantil. Para isso, é necessário considerar os períodos precedentes, já que as atividades não surgem de uma hora para outra, mas pelos interesses e necessidades que se constituem e são incorporados nas relações, seja com o outro ou com o objeto.

No primeiro ano de vida, ocorre a formação dos sistemas sensoriais que permitem a preensão ou ato de agarrar. A complexificação desses movimentos ocorre pela intervenção do adulto, passando para movimentos reiterativos e encadeados. Estes são considerados como "[...] uma conexão de movimentos em ordem consecutiva, sob o controle dos órgãos da percepção" (ELKONIN, 2009, p. 210) e que sucedem na própria relação com o objeto. Os movimentos reiterativos e encadeados são caracterizados por (1) manipulações primárias que necessitam da capacidade de examinar, concentrar, apalpar e ouvir; (2) orientação da atividade para o novo, modificando assim o comportamento da criança; (3) estimulação como sustentação da atividade nova, de modo que, ao se exaurir as possibilidades de manipulação com determinado objeto, perde-se o interesse e automaticamente é interrompida a atividade com ele. Embora essa atividade desenvolva elementos característicos do e para o jogo protagonizado, ela ainda não é considerada enquanto tal (ELKONIN, 2009). 


\section{| Cíntia Regina de Fátima | Flávia Gonçalves da Silva |}

A manipulação primária é substituída para ações com objetos, que é a atividade característica da primeira infância. Nessa mudança de atividade também se modificam as relações entre a criança e o adulto, na qual a comunicação emocional direta (criança adulto) é transferida para a forma mediada com objetos (criança - ações com objetos adulto).

As ações com objetos estão relacionadas com os modos de utilização socialmente determinados que nele se encontram cristalizados, porém esta ação requer a mediação do processo ensino-aprendizagem. Embora as ações fixadas no objeto não sejam necessariamente explícitas, a criança, por si só, é capaz de descobri-las. Destaca-se a importância do processo educacional neste processo, pois a intervenção e colaboração de um indivíduo mais experiente impulsiona o processo de aprendizagem. É importante tanto para ampliar a zona de desenvolvimento próximo do indivíduo (VIGOTSKI, 1988), como mediar os valores e as regras sociais relacionadas ao objeto.

A atividade de ações com objetos está voltada tanto para a aprendizagem do ato, quanto para as relações entre a criança e o adulto. A criança é capaz de identificar previamente as consequências de suas ações em relação ao adulto, sejam elas de aceitação ou rejeição. Durante o processo de aprendizagem do ato primeiro, a criança apreende os aspectos gerais de manipulação de acordo com a sua significação social e, posteriormente, as ações passam a respeitar as condições lógicas, condizentes com as propriedades estáveis do objeto.

Dessa forma, Elkonin (2009) aponta que as ações com objetos, enquanto atividade particular da primeira infância são condições essenciais para o surgimento do jogo protagonizado, que embora seja típico da idade pré-escolar, apresenta suas características elementares e sua origem na primeira infância.

A diversidade de objetos que a criança tem acesso e o nível de relação que estabelece com eles são determinados pela mediação do adulto. Quanto mais objetos a criança se apropria, mais elementos ela possui para atuar em diferentes circunstâncias. No entanto, a atividade não pode ser considerada como ação lúdica, tendo em vista que o objeto não é utilizado como substituto de outro. As ações podem indicar apenas que há um objeto principal na atuação e que os outros exercem função complementar. O autor utiliza o exemplo de uma criança que, em uma determinada situação, calçou os sapatos na bola reproduzindo da mesma forma que se faz com a boneca. O alvo não era a bola substituindo uma boneca, mas ações com o objeto novo - sapato - no qual a bola era um meio para atuar. 


\section{| Cíntia Regina de Fátima | Flávia Gonçalves da Silva |}

Existe um processo de modificação das ações com objetos que perpassa por duas transferências. Na primeira, as ações já são generalizáveis, dessa forma é possível atuar em condições e formas diversificadas. Por exemplo, se antes a criança aprendeu pentear a si mesma, agora realiza este ato também com a boneca, ursinho, entre outros. A segunda possibilidade de transferência é similar a anterior, porém existe a presença de um objeto substituto, provocando a separação entre ação e objeto, logo, a ação passa a ser realizada por meio de diferentes objetos e não apenas aqueles correspondentes ao ato; nesse caso, a criança pode pentear não apenas com o pente, mas com a régua e em diferentes alvos.

A substituição de objetos ocorre quando a criança necessita utilizá-los em uma determinada ação, mas eles se encontram momentaneamente ausentes. Em geral, esses objetos não possuem semelhança com aqueles de posição fixa (como o pente, por exemplo) e primeiro a criança atua com o objeto de acordo com a função lúdica apresentada para, posteriormente, nomeá-lo enquanto tal. Esse processo revela o quanto a substituição de objetos necessita de processos psicológicos complexos (como a imaginação) que ainda não estão consolidados na criança, mas que, em contrapartida, se formam e se desenvolvem por meio do jogo.

Um objeto específico pode substituir diferentes coisas, assim como uma coisa pode ser representada por diferentes objetos. Nessa etapa, a ênfase está na ação e não nas características do objeto. Existem os (1) objetos substitutos que tem a função de complementar os (2) brinquedos temáticos fundamentais. Por exemplo, o (1) palito que é utilizado para "pentear" ou "cortar" o cabelo da (2) boneca. Logo, a importância está em atuar (pentear, cortar, etc.) na boneca. Esse é o fato principal para caracterizar o início da ação como lúdica.

Em determinado momento, a criança começa a identificar suas ações e passa a compará-las e diferenciá-las das ações de outras pessoas. Embora ainda não exista o papel no jogo, essa é uma forma de preparação para ele. A “ideia” da protagonização tem indícios no final da primeira infância expresso por duas situações. A primeira é que a criança atribui o nome de uma determinada pessoa à boneca, conferindo-lhe uma qualidade diferenciada dos outros brinquedos. A segunda se refere ao início da fala protagonizada, isto é, quando ela fala em nome da boneca. Simultaneamente, aparece o papel no jogo e se complexificam as ações lúdicas, porém a sequência das ações tal como ocorre na vida dos adultos, surge no final da primeira infância.

Assim, para Elkonin (2009), o desenvolvimento da ação lúdica na primeira infância, se dá pelo “[...] trânsito da ação univocamente determinada pelo objeto, passando pela 


\section{| Cíntia Regina de Fátima | Flávia Gonçalves da Silva |}

utilização variada deste, para as ações ligadas entre si por uma lógica que reflete a lógica das ações reais na vida das pessoas. Isso já é “o papel em ação" (ELKONIN, 2009, p. 230)".

Embora o jogo protagonizado tenha início na primeira infância, ele se desenvolve ao longo da idade pré-escolar, sendo que nesta etapa atinge o nível mais complexo (ELKONIN, 2009). A partir dos diversos experimentos realizados, o mesmo autor afirma e destaca o papel determinante do adulto na criação das premissas e necessidades, essenciais na transferência para o jogo protagonizado.

Identifica-se a presença de dois momentos simbólicos no jogo protagonizado que caracterizam sua essência (ELKONIN, 2009). O primeiro se refere à capacidade de deslocamento da ação para com outros objetos por meio da metonímia (criança atribui ao objeto a significação lúdica e, do mesmo modo, o denomina e atua sobre ele), ou seja o uso simbólico dos objetos. Nas suas palavras, "o processo de transformação do objeto em brinquedo é justamente o processo de diferenciação do significado e do significante e do nascimento do símbolo" (ELKONIN, 2009, p. 327).

A criança só substitui um objeto por outro, ou ainda, atribui a ele a denominação lúdica quando as propriedades estáveis do objeto correspondem às necessidades básicas para realizar a ação. Logo, não é qualquer objeto que pode realizar a função de substituto. Essas afirmações são confirmadas por Elkonin (2009) quando cita que “[...] a transnomeação nos casos de emprego lúdico do objeto eleva bruscamente a resistência a adotá-la, sobretudo quando as ações lúdicas discrepam dos modos de atuar [...] e carecem de respaldo nas propriedades do objeto lúdico” (ELKONIN, 2009, p. 345).

O segundo momento simbólico do jogo é caracterizado pela representação das relações sociais, em que a criança assume o papel de adulto. Sobre a importância destes dois momentos, o autor aponta que "graças, precisamente, a esse plano duplo de "simbolização", a ação insere-se na atividade e obtém o seu sentido no sistema de relações inter-humanas" (ELKONIN, 2009, p. 356).

Em seus estudos, Elkonin (2009) observou que durante as brincadeiras do período pré-escolar aparecem, basicamente, três modos de utilização dos objetos que estão relacionados com o nível de dificuldade da situação colocada para a criança. O primeiro momento diz respeito à metonímia, logo, as ações estão direcionadas para a denominação lúdica atribuída ao objeto; então, a criança utiliza o lápis de cor como se fosse uma faca, assim como designado.

O segundo caracteriza-se pelo "[...] conflito entre o pré-lúdico e o lúdico do objeto" (ELKONIN, 2009, p. 346), isto é, dependendo do nível de dificuldade colocado para a 
|Cíntia Regina de Fátima | Flávia Gonçalves da Silva |

criança, ao longo da situação ocorre uma desordem em suas ações e ela se confunde a ponto de rejeitar a denominação lúdica. Por exemplo, se na brincadeira são apresentados à criança o lápis e a faca, e inverte a sua denominação, de modo que o lápis passa a ser uma faca e a faca será o lápis, ao se pedir para a criança colorir com o lápis, ela fica confusa com a dificuldade inserida no jogo e ora realiza com o lápis propriamente dito, ora com o objeto nomeado lápis (faca).

Após a rejeição da transnomeação lúdica, surge o terceiro modo de utilização que se refere ao desempenho da ação condizente com a designação real do objeto. Dessa forma, a criança não mais representa com o objeto de acordo com a designação lúdica dada, isto é, o lápis volta a ser lápis que será utilizado para colorir e não cortar.

A relação entre ação, objeto e palavra compõe uma estrutura dinâmica que permite a utilização do objeto de forma lúdica. Contudo, é necessário que estejam cristalizadas na palavra todas as formas de ações com o objeto e que ela seja o princípio norteador, pois somente dessa forma a palavra pode substituir um objeto por outro. Há determinadas situações que a relação objeto/ações pode se sobrepor à relação palavra/ações e essas duas formas de relação mencionadas sofrem significativas modificações na idade pré-escolar. Para Elkonin (2009), “[...] o jogo constitui precisamente uma prática original de operar com a palavra, prática essa em que se produzem mudanças das relações entre o objeto, a palavra e a ação" (ELKONIN, 2009, p. 351).

A característica essencial do jogo protagonizado, que também afeta a simbolização, é a representação de papéis e reprodução do argumento do jogo. Quanto mais velha a criança, mais complexas se tornam as suas ações e o argumento (ou tema do jogo) passa a corresponder a um plano específico de acontecimentos (o conteúdo referente ao tema), de modo que respeitem a uma determinada lógica de execução. As ações das crianças são subordinadas ao papel e ao argumento do jogo, portanto, este (jogo) não existe sem aqueles (papel e argumento). As situações criadas em jogo recebem objetos e ambientes com significações lúdicas. Em presença da situação lúdica, surgem regras internas acordadas entre as crianças e quanto mais velhas, mais regras são incorporadas e mais amplas se tornam as situações lúdicas.

O jogo só faz sentido para a criança quando, por meio da ficção, representa o homem. A partir de seus experimentos, Elkonin (2009) também assinala duas importantes características do jogo. A primeira é a interpretação do papel como o motivo principal do jogo e condição para sua existência. A segunda característica é a mudança na percepção da criança sobre seu papel no jogo. Somente no final da idade pré-escolar ela é capaz de 


\section{| Cíntia Regina de Fátima | Flávia Gonçalves da Silva |}

diferenciar a relação eu - papel; por exemplo, quando se propõe os jogos de si mesmo (em que representa o papel dela mesma), a criança na primeira infância se recusa a brincar. Já na idade pré-escolar, ela aceita com determinada crítica, como se entendesse a proposta, mas não fizesse sentido para ela.

Elkonin (2009) faz inferências relevantes para compreensão do jogo. A primeira é que a sua essência está na representação de um papel, não sendo necessária a criação de uma situação lúdica especial na qual há substituição de um objeto por outro. Logo, a faca pode continuar sendo faca, o lápis sendo lápis, entretanto, devem representar ações de uma determinada pessoa. Na segunda, afirma a reconstituição das relações interpessoais como uma característica básica do jogo. A terceira inferência é que o sentido do jogo se modifica a cada etapa, de modo que, para a criança pequena, o sentido está nas ações da pessoa interpretada; na idade mediana, ele se concentra nas relações da pessoa representada com os outros; e nas crianças mais velhas o sentido se volta para as relações típicas da mesma pessoa. A quarta afirma a existência de regras no jogo que estão relacionadas à conduta social. A quinta determina que a representação do papel requer a presença de relações reais para a criança.

No início, o jogo está direcionado para as relações do adulto íntimo da criança, depois, entre adultos e, finalmente, da criança com o adulto. Essa inferência, segundo Elkonin (2009), supõe que o desenvolvimento da consciência individual da criança é produto do jogo. A última inferência revela que a atitude da criança, em presença ao jogo, também se desenvolve e são constatadas pela manifestação de discussões e críticas no jogo das crianças mais velhas.

Assim, para Elkonin (2009), o jogo perpassa por um processo que pode ser sintetizado em duas fases fundamentais e assim as descreve:

\footnotetext{
$\mathrm{Na}$ primeira (de 3 a 5 anos), o conteúdo fundamental do jogo são as ações objetais, de orientação social, correspondentes à lógica das ações reais; na segunda (de 5 a 7 anos), as relações sociais estabelecidas entre as pessoas e o sentido social de sua atividade, correspondentes às relações reais existentes entre as pessoas (ELKONIN, 2009, p. 301).
}

O jogo reflete as relações sociais, portanto não se trata genuinamente da criação, mas da "reconstituição original da realidade vivida" (ELKONIN, 2009, p. 318). Isso implica em seguir regras de comportamento refletidas de ações reais. Por isso o autor desconsidera qualquer afirmação que separa e apresenta como contrários o mundo imaginário (jogo) da criança e o mundo real. Nesse sentido, todo jogo protagonizado apresenta regras, mesmo que de forma implícita, estando diretamente relacionado com as 


\section{| Cíntia Regina de Fátima | Flávia Gonçalves da Silva |}

regras submetidas ao papel assumido pela criança. Portanto, quanto mais complexo é o conteúdo do jogo, mais elaboradas e difíceis são as regras (ELKONIN, 2009).

Partindo dessa perspectiva, o autor afirma que os jogos na idade pré-escolar se desenvolvem de argumento e papéis explícitos e regras ocultas para jogos com regras explicitas e situações lúdicas latentes, de forma que o argumento (ou tema) apenas denomina o jogo. Somente na idade escolar as regras são completamente desprendidas do argumento.

Em alguns dos seus experimentos, Elkonin (2009) concluiu que o argumento do jogo é essencial para a criança assimilar as regras, tendo em vista que a auxilia no cumprimento das regras e amplia as possibilidades de controlar suas ações. As regras, sem o argumento, não fazem sentido para a criança, por isso a dificuldade em se submeter a elas. $\mathrm{O}$ autor ilustra essa afirmação por meio do experimento em que a criança apresentou nos jogos de corrida dificuldade de se submeter às regras. Ela corria antes de disparar o sinal ou demorava para atender o comando. Após inserir o argumento, isto é, quando se tornou um jogo de locomotiva, a criança não apenas adotava as regras com maior facilidade, como suas ações também passaram a corresponder aos movimentos e sons emitidos pela locomotiva.

$\mathrm{Na}$ criação do jogo, primeiro manifesta-se o argumento para depois, durante o processo, estabelecer as regras. A capacidade de elaborar as regras antes de iniciar o jogo surge somente no final da idade pré-escolar. Ao teorizar sobre o jogo protagonizado, Elkonin (2009) aponta suas determinações no desenvolvimento psíquico da criança, sendo destacadas, neste trabalho, aquelas que se apresentam mais relevantes.

Segundo Elkonin (2009), o jogo como atividade, não corresponde diretamente às necessidades da criança. A criança quer agir no mundo adulto, mas diante de suas possibilidades físicas e psíquicas, ela se apropria do brincar para atendê-las imediatamente. Dessa forma, pode-se dizer que o jogo é mediador entre a criança e suas necessidades. Ele está relacionado não apenas ao nível de desenvolvimento que a criança pode atingir na idade pré-escolar (no qual surgem novos interesses e conteúdos na ação infantil), mas, sobretudo, ao impacto emocional provocado pelos sentidos constituídos da/na atividade humana e à conscientização da posição que se ocupa na sociedade. O jogo protagonizado proporciona à criança mudanças no pensamento, tornando-o mais complexo. Representar o papel de adulto permite à criança vivenciar diferentes formas de se comportar, modificar suas atitudes e, ao mesmo tempo, adotar uma posição como referência que não seja a dela mesma. 


\section{| Cíntia Regina de Fátima | Flávia Gonçalves da Silva |}

Elkonin (2009) aponta que, por meio do jogo protagonizado, a criança aprende a respeitar as relações construídas no papel. Por exemplo, se fora do contexto de jogo as crianças estão brigadas, mas na brincadeira representam o papel de amigas, elas atuam de acordo com as regras e argumentos do jogo. Assim como, ao atuar com o objeto de acordo com sua significação lúdica, a criança aprende a respeitar o sentido atribuído ao objeto, logo, uma vez determinado que o lápis representará uma seringa e será utilizada apenas pelo médico, independente de quem assumir o papel, deve-se preservar o combinado.

Elkonin (2009) também apresenta os estudos de Zaporózhets para ilustrar a importância do jogo protagonizado na realização do movimento, comprovando que, ao assumir um determinado papel, a criança obtém mais sucesso no comportamento motor, modificando inclusive a qualidade do movimento realizado.

Dentre as tantas contribuições do jogo para o processo de constituição da criança, também são apresentadas as transformações que ocorrem em seu comportamento mediado pelo trabalho coletivo versus independência realizado na atividade. No jogo, a criança aprende a exercer o trabalho em grupo e agir como um adulto independente, capaz de controlar e modificar determinados comportamentos, a partir de modelos que podem orientar as ações durante o processo lúdico, bem como compará-lo.

O desenvolvimento da coletividade na criança se dá, especialmente, na organização da estrutura do jogo protagonizado, pois é necessário: entrar em acordo sobre um tema que atenda aos interesses de todos os integrantes; atribuir os papéis de modo que todos cumpram e sintam-se empenhados; acordar sobre os significados dos objetos em jogo e agir como tal; distribuir os objetos correspondentes ao papel representado; atuar de forma a respeitar as regras e situações criadas para o jogo; e, finalmente, ser capaz de controlar seu comportamento e de seus parceiros (ELKONIN, 2010). Assim, quanto mais desenvolvido o jogo, maior será a complexidade dessa organização.

O desenvolvimento intelectual proporcionado no jogo não está vinculado à aprendizagem de operações e sistemas, mas "[...] por la posibilidad de cambiar las posiciones de niño hacia la realidad que lo rodea" (ELKONIN, 2010, p. 132), de tal forma que a criança deixa de perceber o mundo a partir de si mesma e adquire novos olhares sob diferentes contextos.

Em síntese, a atividade lúdica, para Elkonin, é a representação de um papel, com ou sem a substituição do objeto. É por meio do jogo que a criança apreende a realidade humana e assimila as funções psíquicas, tipicamente humanas, que possibilitam sua ação consciente no mundo. 


\section{AS CONTRIBUIÇÕES DE ELKONIN PARA EDUCAÇÃO FÍSICA ESCOLAR}

Ao longo de toda sua obra, Elkonin apresenta a importância do adulto para o surgimento das atividades, no sentido de atuar a partir das necessidades e interesses da criança. Em função disso, o professor se configura como mediador essencial tanto no sistema de relações criança-objeto social quanto criança-adulto social. O professor de Educação Física possui conhecimentos relacionados ao movimento, mas há pouco enfoque na sua formação sobre o desenvolvimento da criança concebendo-a em sua totalidade. Nesse sentido, esse trabalho busca problematizar sobre esses aspectos e sua importância para o professor de Educação Física e dentro dos seus limites, propor algumas contribuições para as aulas por ele ministradas. Considerando as inúmeras linguagens da cultura corporal, bem como outras contribuições que a teoria de Elkonin pode oferecer, mas que não foram contempladas nesse estudo, é necessário que o professor faça a leitura (das contribuições propostas) e a partir dela, crie e reelabore-as de acordo com a especificidade da aula.

É imprescindível conhecer as atividades principais com o mesmo grau de aprofundamento em todos os períodos e ao mesmo tempo, a partir da periodização proposta pelo autor, criar atividades que desenvolvam as possibilidades de cada época, preparando a criança para aquelas que estão por vir, pois a aprendizagem, assim como o desenvolvimento, se dá por meio de um trabalho intencional em que o aprendiz é entendido em sua totalidade; pelas mediações que o constitui e não pela imediaticidade.

Os conhecimentos produzidos por Elkonin (assim como pela psicologia históricocultural) no que se refere à atividade principal permite o professor identificar em qual período a criança se encontra e qual sistema predomina na relação da criança com o mundo. Dessa forma, o professor, nas atividades propostas em aula, pode tanto explorar as formas de relações típicas de cada período quanto preparar a criança para o novo sistema de relações, tornando possível o diálogo entre os períodos e épocas. $\mathrm{Na}$ aula de Educação Física, por exemplo, é possível ora explorar mais os materiais específicos de cada manifestação da cultural corporal (bolas de diferentes tamanhos, fitas, arcos, movimentos típicos de cada), dando destaque à relação criança-objeto social, ora enfatizar as relações entre as crianças e das crianças com os adultos, durante as atividades.

Além do sistema de relações predominante, identificar as épocas e períodos que compõem a periodização permite ao professor compreender as especificidades da formação humana e do processo educacional, sendo capaz de organizar os conteúdos da 


\section{| Cíntia Regina de Fátima | Flávia Gonçalves da Silva |}

Educação Física considerando os aspectos motivacionais e intelectuais da criança. A partir das considerações de Elkonin, pode-se afirmar, por exemplo, que não se deve ensinar voleibol para uma criança de 5 anos valorizando a técnica e o movimento correto. Ela dificilmente será capaz de se submeter às regras tão complexas como dessa modalidade esportiva e, possivelmente, ainda não possui o tipo de habilidade motora com a bola que o esporte exige. A aula deverá ser coerente com as suas possibilidades (neste caso, considerar que o período é mais sensível para atividades ligadas à imaginação explícita e regras mais ocultas), sempre em busca de saltos qualitativos no seu desenvolvimento.

Ao analisar a estrutura de desenvolvimento do jogo é possível perceber que embora as atividades possuam particularidades que as diferenciam, em cada etapa, elas também se inter-relacionam e são interdependentes de tal forma que, a cada período, adquirem maior complexidade devido ao desenvolvimento psíquico assimilado nas etapas anteriores. Subentende-se que qualquer atividade, para ser apreendida e para promover o desenvolvimento, exige uma estrutura que parta daquilo que o aluno já sabe. Em função disso, quando o professor se propõe a ensinar um elemento da ginástica, ele deve conhecer as habilidades prévias do aluno, apresentar atividades que são articuladas e possuem uma estrutura dinâmica, mas que tenha uma determinada lógica de execução, no sentido de facilitar o processo de aprendizagem e desenvolver a complexidade dos movimentos. Quando o professor, por exemplo, decide ensinar a estrela (elemento da ginástica) para um aluno que nunca realizou o movimento, como uma primeira atividade pode propor ações de quadrupedia (imitar bichos que são familiares ao aluno e, com isso, auxiliar no fortalecimento dos membros); na segunda, pode colocar uma caixa e a criança passar de um lado para o outro com os pés juntos ou alternados; na terceira, com ajuda do professor, segurando o quadril da criança, auxiliar na passagem de um lado a outro com pernas alternadas; e na quarta, fazer um corredor de colchões e deixar a criança realizar a estrela sozinha no sentido de alinhar o movimento. Essa é uma sequência pedagógica de ensino que perpassa por uma evolução de complexidade, facilitando a compreensão e familiarização do movimento, na qual mantém dinamicidade, em que uma precisa da outra e quanto maior a complexidade com que se realiza cada uma delas, melhor será o resultado final.

O autor também aponta outras estratégias referentes ao jogo no período préescolar, facilitadoras do processo ensino-aprendizagem e que atuam diretamente na formação da criança: o argumento, a substituição de objetos e a representação de papéis. Entende-se que estes elementos constituintes do jogo, devem ser apropriados como 


\section{| Cíntia Regina de Fátima | Flávia Gonçalves da Silva |}

recursos pedagógicos no ensino da Educação Física. Como, por exemplo, atribuir um tema (argumento) para a aula, "a aventura na floresta" e, dentro desse argumento, aprender vários elementos da ginástica e encontrar distintas situações que podem ocorrer na floresta (como na sequência pedagógica descrita acima) que serão reproduzidas pela criança. Além disso, é admissível atribuir novos significados aos objetos empregados. Por outras palavras, os colchões laterais podem representar paredes, constituídas de plantas (árvores e flores), que, se encostar, a criança vai cair e danificar a natureza, ou, que no chão entre esses colchões existe um lago muito fundo, que as crianças precisam passar por ele de ponta cabeça, mas, sem cair dentro do lago. As regras consistem em (1) atravessar de ponta cabeça e não cair no lago, pois este é fundo e as crianças podem se afogar e (2) não encostar nos colchões.

$\mathrm{Na}$ representação de papel, para a criança compreender o movimento, é possível utilizar um modelo, seja em história oral, foto ou vídeo, em que a mesma deve "fingir" ser aquela pessoa ou coisa e representá-la. São elementos que vão auxiliar no entendimento e execução. A utilização de modelo para o ensino de determinado movimento ou para refletir sobre determinados valores sociais demonstram-se eficazes no processo educacional sem, no entanto, supervalorizar e/ou criar padrões.

Os ganhos qualitativos proporcionados são apresentados ao longo do trabalho. Dessa maneira, fica clara a importância da presença do jogo como meio e como fim no processo ensino-aprendizagem. O jogo protagonizado como um recurso pedagógico (isto é, como meio), tal como no exemplo supracitado, utiliza-se da sua estrutura (relação entre imaginação e regras) para ensinar outros conteúdos para a criança. Dessa forma, muitos dos conteúdos da Educação Física que seriam impossíveis de ser ensinados devido o predomínio das regras, se tornam possíveis na medida em que se reelabora a forma de ensiná-los.

Já como fim, o objetivo está voltado para ensino do jogo propriamente dito e não como forma de lecionar outros elementos da cultura corporal. Assim, o propósito consiste em ensinar a criança o jogo protagonizado e apresentar a ela novas possibilidades que ela não conhece. Por exemplo, a criança muito pequena ainda não sabe brincar com um objeto sem a presença dele no jogo, logo, é papel do adulto ensiná-la novas estratégias, neste caso, substituir um objeto por outro assim como propor a representação de diferentes papéis.

Elkonin também apresenta uma concepção importante para a Educação Física: superar a dicotomização que, muitas vezes nesta área, se faz do aluno. A disciplina em questão, muitas vezes se preocupa apenas com a educação motora, com o ensino de 


\section{| Cíntia Regina de Fátima | Flávia Gonçalves da Silva |}

habilidades e com a melhora da capacidade física, mas desconsidera que a criança ou adolescente, ao chegar à escola, já possui determinados conhecimentos e cultura. Desse modo, deve-se não só considerar o repertório motor do aluno, mas também analisá-lo como um processo histórico, para que se possa ensinar a linguagem da cultura corporal. Pois, tão importante quanto conhecer e analisar o movimento a ser ensinado, é conhecer a história de vida do sujeito a quem se ensina, quais suas experiências, suas relações, o que ele pensa e conhece. Para além do movimento, há uma criança, adolescente ou adulto que é constituído por uma história (inclusive relacionada à prática que se pretende ensinar) que deve ser conhecida e usada como ponto de partida para o ensino.

A partir disso, o professor pode estabelecer metas (o que quero que esse indivíduo aprenda? Como contribuir no seu desenvolvimento?), ensinar e questionar determinados valores, regras sociais e concepções de homem e mundo. Portanto, a especificidade da Educação Física é o movimento em sua totalidade, entendido não apenas como movimento muscular, seja cinético ou tônico, mas como uma relação dialética entre as dimensões motoras, cognitivas e afetivas, que compõem o indivíduo.

Há outras duas questões importantes, que ao fazer a leitura de Elkonin e articula-la com a Educação Física, merecem destaque. Primeiro é que conhecer e ter habilidades corporais como a coordenação motora, e capacidades físicas (equilíbrio, força, resistência, flexibilidade) é importante na vida cotidiana do indivíduo. Ao ser corpo, ele precisa aprender a lidar com seu corpo no mundo e com o corpo do outro. Porém, cada vez mais as crianças e jovens possuem menos habilidade e conhecimento sobre si. Por exemplo, com o avanço da tecnologia as crianças costumam brincar muito mais com os equipamentos eletrônicos, abandonando a cultura do movimento. Os jogos e variadas funções em celulares, computadores, videogames, intensificam o abandono do movimento muscular (que exige várias/desenvolve habilidades) e da relação com os outros, restringindo-se à relação criança-objeto social, que embora seja social (no sentido de produção humana), não necessariamente, são socializadores.

Para além das questões de saúde (fisiológicas e biológicas), pelas concepções de Elkonin, é possível apresentar a importância do corpo, do movimento e das relações do indivíduo, especialmente na criança, pois é por meio dele que temos acesso a tudo que foi produzido pela humanidade ao longo do tempo. Basta considerarmos a atividade manipulativa com objetos na primeira infância e a relação lúdica que a criança estabelece no período pré-escolar. Empurrar, saltar, correr, subir, empilhar são movimentos que 


\section{| Cíntia Regina de Fátima | Flávia Gonçalves da Silva |}

possibilitam a criança conhecer os objetos, a relação que há entre eles, além de conhecer suas possibilidades e limites, propor novos desafios, superar medos.

O desenvolvimento de habilidades motoras possibilita e ao mesmo tempo é possibilitado pelo desenvolvimento dos processos psíquicos, da aprendizagem em se relacionar com o outro e consigo mesma. A comunicação da criança no período pré-escolar depende de forma significativa do movimento, para expressar seus desejos, angústias, formas como ela compreende o mundo. Não basta para criança, por exemplo, falar que algo é grande, ela precisa abrir os braços e demonstrar motoramente o que ela fala.

O processo de desenvolvimento do indivíduo para a psicologia histórico cultural se direciona para o controle da própria conduta, que vai sendo aprendido gradativamente ao longo dos períodos (de comportamentos reflexos e espasmos motores logo que nasce, gradativamente a criança aprende novos comportamentos expressos de forma intencional). Nesse sentido, a criança no período pré-escolar ainda não tem total domínio de seu comportamento, sendo necessário possibilitar sua expressão, em sua totalidade (motora, afetiva, intelectual), e ao mesmo temo auxiliá-la a controla-lo, sendo as atividades lúdicas (sempre constituídas por regras) um recurso importante nesse processo. No entanto, para além dessa atividade, é importante possibilitar a criança o movimento nas demais atividades pedagógicas. Exigir que a criança fique parada pode exigir da mesma muito mais energia e autocontrole, que geralmente ela ainda não tem, que possibilitá-la se movimentar. Tal exigência à criança pode justificar os comportamentos que são denominados por professores na Educação Infantil de indisciplina, quando na verdade, se exige dela muito mais que suas possibilidades.

Ainda sobre os jogos eletrônicos, estes restringem o contato do indivíduo com o mundo e com a cultura produzida historicamente. Em outras palavras, a criança possui acesso ao mundo de hoje, ao que possuímos de mais atual e tecnológico, mas sua apropriação ao que foi construído no passado e nos constitui como humanos (por exemplo, a cultura corporal) é cada vez mais escassa e limitada se não houver mediação de um adulto.

A relação entre o jogo lúdico a partir da representação da realidade vivenciada pela criança e do lúdico possibilitado pelo jogo eletrônico não são excludentes; ambos podem promover desenvolvimento e aprendizagem na criança de variadas formas e particularidades da realidade. Apesar da criança poder se projetar num personagem de um jogo eletrônico, essa representação é pré determinada a partir do argumento e conteúdo desse jogo, que já vem pronto. Assim, como a imaginação fica presa ao argumento e 
Dossiê: Diálogos interdisciplinares em Psicologia da Educação

| A atividade lúdica no desenvolvimento da criança: contribuições de Elkonin para a Educação

Física Escolar|

\section{| Cíntia Regina de Fátima | Flávia Gonçalves da Silva |}

conteúdo do jogo, a ação motora se restringe ao movimento dos dedos. Por outro lado, o jogo eletrônico exige habilidades e agilidade de raciocínio e imaginação num nível mais abstrato que, quando realizado com a mediação do adulto, pode promover maior desenvolvimento dos processos citados.

O segundo ponto é que a Educação Física também é importante para desenvolver a criatividade das crianças por meio de atividades com objetos da cultura e com o seu corpo, tendo em vista que cada vez mais os brinquedos (do mercado) tem o propósito de incentivar o consumo e é multifuncional, impedindo o processo de criação, da relação com o adulto (que muitas vezes não sabe utilizá-lo) e até com outras crianças. Estes brinquedos, por se esgotarem em suas próprias funções, fazem com que a criança perca o interesse muito rápido. Por exemplo, as bonecas já choram, falam, fazem xixi e muitas outras funções que, antemão, seriam fruto da reprodução e imaginação da criança. Por meio da Educação Física ela tem a possibilidade de conhecer jogos e brincadeiras, esportes, danças, lutas, que foram construídos pela humanidade ao longo da história e que a permitem criar e recriar com objetos, mas também sem eles.

Todas as possibilidades pedagógicas sugeridas vão ao encontro dos objetivos e orientações colocados no Referencial Curricular Nacional para a Educação Infantil (1998), que destaca o brincar como uma atividade importante para o desenvolvimento da criança, por possibilita-la se apropriar do mundo simbólico, ao mesmo tempo em que por esta atividade é possível aprender vários outros conteúdos escolares. A organização do conteúdo no referido documento se faz a partir de dois âmbitos, Formação Pessoal e Social e Conhecimento de Mundo, a partir dos seguintes eixos: Movimento, Artes visuais, Música, Linguagem oral e escrita, Natureza e sociedade, Matemática. Tal organização deve possibilitar a Educação Infantil:

- desenvolver uma imagem positiva de si, atuando de forma cada vez mais independente, com confiança em suas capacidades e percepção de suas limitações;

- descobrir e conhecer progressivamente seu próprio corpo, suas potencialidades e seus limites, desenvolvendo e valorizando hábitos de cuidado com a própria saúde e bem-estar;

- estabelecer vínculos afetivos e de troca com adultos e crianças, fortalecendo sua auto-estima e ampliando gradativamente suas possibilidades de comunicação e interação social;

- estabelecer e ampliar cada vez mais as relações sociais, aprendendo aos poucos a articular seus interesses e pontos de vista com os demais, respeitando a diversidade e desenvolvendo atitudes de ajuda e colaboração;

- observar e explorar o ambiente com atitude de curiosidade, percebendo-se cada vez mais como integrante, dependente e agente transformador do meio ambiente e valorizando atitudes que contribuam para sua conservação; 
- brincar, expressando emoções, sentimentos, pensamentos, desejos e necessidades;

- utilizar as diferentes linguagens (corporal, musical, plástica, oral e escrita) ajustadas às diferentes intenções e situações de comunicação, de forma a compreender e ser compreendido, expressar suas idéias, sentimentos, necessidades e desejos e avançar no seu processo de construção de significados, enriquecendo cada vez mais sua capacidade expressiva;

- conhecer algumas manifestações culturais, demonstrando atitudes de interesse, respeito e participação frente a elas e valorizando a diversidade (BRASIL, 1998, p. 63).

A partir de tais objetivos descritos no documento que orienta a Educação Infantil no Brasil, entende-se que as reflexões apresentadas nesse artigo estão condizentes com ele, explicitando ainda mais a importância da Educação Física nesse nível educacional e das atividades lúdicas, como conteúdo e fim pedagógico.

\section{CONSIDERAÇÕES FINAIS}

A partir dos estudos de Elkonin, foi possível apresentar a importância das atividades lúdicas (como conteúdo da educação física escolar) no desenvolvimento da criança e algumas estratégias pedagógicas para facilitar o ensino de conteúdos da cultura corporal na Educação Infantil. Esse estudo também mostrou a importância de o professor de Educação Física se apropriar dos conhecimentos da psicologia, nesse caso, da psicologia histórico-cultural, para conhecer o homem e o processo de aprendizagem e desenvolvimento.

As atividades lúdicas possibilitam ao professor de Educação Física compreender que os jogos e brincadeiras podem, além de ser conteúdos e recursos pedagógicos, promover o desenvolvimento integral da criança, especialmente quando direcionado para tal finalidade. As proposições da psicologia histórico-cultural evidenciam a indissociabilidade dos aspectos biológico, social e psicológico na compreensão do indivíduo, permitindo a cultura corporal contribuir para a formação humana.

Compreender o indivíduo em sua totalidade, considerando as dimensões que constituem o homem, como sendo indissociáveis, permite compreender a Educação Física para além do aspecto motor. Torna admissível a concepção do educar pelo movimento, superando as teorias que se limitam à compreensão de corpo versus mente. Dessa forma, é importante o professor de Educação Física se apropriar dos conhecimentos produzidos pela psicologia histórico-cultural, pois elucida o processo de desenvolvimento humano e, ao mesmo tempo, fornece subsídios essenciais para os profissionais que atuam na formação do sujeito. 


\section{| Cíntia Regina de Fátima | Flávia Gonçalves da Silva |}

Esses conhecimentos permitem que o professor entenda o que é desenvolvimento e que este provém da aprendizagem, sendo necessário, para promovê-lo, considerar as especificidades de cada etapa e, sobretudo, as particularidades do sujeito. Logo, não se pode dizer que qualquer atividade promoverá, por si só, o desenvolvimento. Para que isto ocorra, é necessário considerar aspectos históricos tanto do sujeito, da atividade promovida e do processo da própria atividade. Portanto, o processo educacional deve estar em constante (re)construção e o professor sempre em busca de novos conhecimentos que enriqueça sua atuação profissional. A partir disso, sugerem-se estudos empíricos que possam contribuir para a discussão da temática, relacionando-os, especialmente, à Educação Física, o cotidiano do professor em sala de aula e do aluno em seus aspectos singulares.

\section{REFERÊNCIAS}

AYOUB, E. Reflexões sobre a educação física na educação infantil. Revista Paulista de Educação Física, São Paulo, supl. 4, p. 53-60, 2001. Disponível em: $<$ http://citrus.uspnet.usp.br/eef/uploads/arquivo/v15\%20supl4\%20artigo6.pdf $>$. Acesso em: 02 jun. 2011.

AYOUB, E. Narrando experiências com a Educação física na Educação Infantil. Revista Brasileira de Ciências do Esporte, Campinas, v. 26, n. 3, p. 143-158, 2005. Disponível em: <http://www.rbceonline.org.br/revista/index.php/RBCE/article/viewArticle/165>. Acesso em: 16 maio 2011.

BRASIL. Lei de Diretrizes e Bases da Educação Nacional. Brasília: MEC/SEF, 1996.

BRASIL. Referencial Curricular Nacional para a Educação Infantil. Brasília: MEC/SEF, 1998.

BRASIL. Lei $\mathbf{n}^{\mathbf{0}} \mathbf{1 2 . 7 9 6}$, de 4 de abril de 2013. Altera a Lei $\mathrm{n}^{\circ}$ 9.394, de 20 de dezembro de 1996. Brasília: Casa Civil, abr. de 2013. Disponível em: $<$ http://www.planalto.gov.br/ccivil 03/ ato2011-2014/2013/lei/112796.htm>. Acesso em: 06 dez. 2017.

CASTELlani FILHO, L. [et al.]. Metodologia do ensino de Educação Física. São Paulo: Cortez, 2001.

ELKONIN, D. B. Psicologia do jogo. Tradução de Álvaro Cabral. 2. ed. São Paulo: Editora WMF Martins Fontes, 2009.

ELKONIN, D. B. Hacia el problema de la periodización del desarrollo en la edad infantil. In: ROJAS, L. Q.; SOLOVIEVA, Y (Comp.). Las funciones psicológicas en el desarrollo del niño. México: Trillas, 2009a. p. 129-137. 
ELKONIN, D. B. Problemas actuales en la psicología del juego en la edad preescolar. In: SOLOVIEVA, Y.; ROJAS, L. Q (Comp.). Antología del desarrollo psicológico del niño en edad preescolar. México: Trillas, 2010. p. 191-209.

KISHIMOTO, T. M. Jogo, brincadeira e a educação física na pré-escola. Motrivivência, Florianópolis, ano 8, n. 9, p. 66-77, 1996. Disponível em: $<$ http://www.periodicos.ufsc.br/index.php/motrivivencia/article/view/5656>. Acesso em: 18 jul. 2012.

LAZARETTI, L. M. D. B. Elkonin: vida e obra de um autor da psicologia históricocultural. São Paulo: Edidora Unesp, 2011.

NISTA-PICCOLO, V. L.; MOREIRA, W. W. Corpo em movimento na educação infantil. São Paulo: Cortez, 2012.

PINTO, L. M. S. M. Sentidos do jogo na educação física escolar. Motrivivência, Florianópolis-SC, ano 8, n. 9, p. 95-108, 1996. Disponível em: $<$ http://www.periodicos.ufsc.br/index.php/motrivivencia/article/view/5659>. Acesso em: 18 jul. 2012.

VIGOTSKI, L. S. Aprendizagem e desenvolvimento intelectual na idade escolar. In: VIGOTSKI, L. S.; LEONTIEV, A. N.; LURIA, A. R. Linguagem, desenvolvimento e aprendizagem. São Paulo: Ícone, 1998. p. 103-118. 